\title{
MAIS OU MENOS NEGRA? QUeSTÕES DE NEGRITUDE, tradução e a poesia de Harryette Mullen
}

\author{
More or less black? Questions of blackness, \\ translation and Harryette Mullen's poetry
}

\author{
Lauro Maia Amorim*
}

\begin{abstract}
RESUMO
Este trabalho discute questões oriundas da tradução, por mim realizada, de uma seleção de poemas de Harryette Mullen, autora afro-americana contemporânea em ascensão, cuja densa poesia versa sobre a oralidade negra, o experimentalismo da escrita, a música afro-americana, além de focalizar temas como a representação da sexualidade feminina (negra). Um dos aspectos complexos de sua poesia é a noção de miscigenação ou mestiçagem, concebida como um argumento estético e como uma condição constitutiva da identidade multirracial dos norte-americanos. Essa noção viabiliza uma textualidade que questiona a inteligibilidade acessível que geralmente se espera da poesia negra americana, na medida em que mosaicos de vozes dissonantes são trazidos à tona em seu texto, tornando-o difícil de categorizar. No Brasil, especialmente entre os afro-brasileiros mais engajados, tem-se criticado o louvor à noção de miscigenação, por esta supostamente participar da sustentação do mito da democracia racial. Com base nesses aspectos, investiga-se em que medida seria um desafio traduzir sua poesia - fundamentada na miscigenação e no hibridismo como construto estético - ao se levar em conta o lugar discursivo dos leitores identificados com uma estética afro-brasileira, mormente crítica da noção de miscigenação. Do ponto de vista tradutório, avalia-se em que medida a sua poesia poderia ser lida pelo discurso cultural vigente no Brasil, inclinado a favorecer a miscigenação como uma concepção integral da identidade nacional, como uma poética sedutoramente experimental. Em

• UNESP - São José do Rio Preto.
\end{abstract}


face disso, questiona-se se essa perspectiva tornaria a sua poesia "menos negra" para os padrões literários afro-brasileiros.

Palavras-chave: tradução; literatura afro-americana; miscigenação.

\begin{abstract}
This paper addresses issues regarding my translation of selected poems by Harryette Mullen, a rising African-American contemporary poet, whose dense poetry works on the black oral tradition, the experimentalism of writing, the (African-American) pop music, in addition to delving into issues such as the representation of (black) female sexuality. One of the complex aspects of her poetry is the notion of miscegenation, conceived as an aesthetic argument and as a constitutive condition of the identity of multiracial Americans. This concept establishes a textuality that questions the accessible intelligibility generally expected from black American poetry, insofar as a mosaic of dissonant voices are brought to light in her text, which makes it difficult to categorize. In Brazil, especially among politically engaged Afro-Brazilians, there has been criticism towards the praise of miscegenation, since the latter has been considered to support of the myth of racial democracy. Building on these aspects, we investigate the extent to which it is a challenge to translate her poetry - based on miscegenation and hybridity as aesthetic constructs - especially when taking into account the discursive locus of readers identified with an Afro-Brazilian aesthetic, particularly critical of miscegenation. From the point of view of translation, we evaluate the extent to which her poetry could be read by the predominant cultural discourse in Brazil, inclined to favor miscegenation as an integral concept of national identity, as a seductively experimental poetry. In view of this, one wonders whether this perspective makes hers poetry "less black" for Afro-Brazilian literary standards.
\end{abstract}

Keywords: translation; African-American literature; miscegenation.

\title{
INTRODUÇão
}

Este trabalho aborda certos aspectos conflituosos relacionados à tradução, por mim realizada, de poemas selecionados ${ }^{1}$ de Harryette Mullen,

${ }^{1}$ Para atender aos objetivos deste artigo, o autor discute a tradução de apenas um poema da autora, dentre uma seleção e tradução de cerca de 20 poemas, não apresentados neste trabalho por razões de espaço. 
autora afro-americana contemporânea, cujo trabalho retrata a cultura pop e pós-moderna, o experimentalismo da escrita, os saberes populares, incluídos os estereótipos, as frases feitas, nursery rhymes, double entendres, e o universo da música e da literatura (afro-)americanas, além de focalizar temas como a representação da sexualidade feminina (negra) e a violência, tanto física quanto midiática, por meio de jogos de palavras e de uma linguagem altamente disfórica. A autora explora os limites da textualidade da poesia negra, conduzindo a uma análise das relações entre linguagem e realidade, e de como identidades são formadas e instituídas. De acordo com Tremblay-McGaw,

A escrita de Mullen cria textos que permanecem abertos à ambiguidade, à dificuldade, e à diferença. Sua escrita se engaja na crítica política e social com atenção especial às questões raciais, de gênero e do discurso da comoditização, ao mesmo tempo em que se deleita com os prazeres de um jouissance linguístico infinito (TREMBLAY-MCGAW, 2010, p. 71).

Tendo como ponto de partida um poema, por mim traduzido para o português, e as questões suscitadas pela poética de Mullen, pretendo analisar em que medida a tradução de sua poesia conduz a determinados conflitos, considerando-se os lugares discursivos dos leitores identificados ou não com uma estética literária afrodescendente no Brasil. Questiona-se até que ponto essa (não-)identificação exerceria alguma influência no modo como sua poesia poderia ser lida em tradução. Com o objetivo de discutir essa questão, analisam-se os aspectos estéticos que caracterizam sua poética por meio da tradução proposta.

A tradução da poÉtica de Harryette Mullen: Refrações e hibridismo

A poética de Mullen faz uma releitura dos clichês das relações estético-raciais, trazendo à tona tanto alusões à cultura afro-americana, e sua relação com a cultura pop globalizada, quanto um questionamento do papel circunscrito à poesia negra de representar a realidade tal como ela seria (marcada pelo racismo e pela exclusão do negro), para que ela mesma seja aceita como tal. Sua poesia revela uma problematização da suposta transparência da linguagem, subvertendo as expectativas em torno de uma poética (que se espera) "realista". Mullen enfatiza o jogo com os significantes (tanto quanto com os significados), num jogo de espelhos que refratam, mais 
do que refletem, os signos da cultura (afro-)americana, por meio de alusões indiretas aos saberes da mídia e da cultura pop, e de experimentações com o jazz, o blues e a cultura hip-hop.

A experimentação formal em Muse \& Drudge, obra de 1995, revela a influência do estilo criptográfico da poesia de Gertrude Stein e do Language Poetry, mas sempre imbuída de uma relação crítica com questões de identidade cultural. Frost considera, por exemplo, que, em Muse \& Drudge,

\begin{abstract}
Harryette Mullen compôs um longo poema como o blues: fragmentado e improvisatório, e disjuntivo nas suas continuidades. Mullen mistura as influências de grupos avant-garde frequentemente considerados de modo isolado: tal como os poetas do Black Arts Movement, Mullen experimenta com o idiomatismo da língua falada, mas, como os escritores do Language Poetry, ela promove sua crítica cultural rejeitando as regras da sintaxe e exibindo um jogo distintivamente visual, trocadilhista e alusivo com a linguagem (FROST, 1998, p. 465).
\end{abstract}

O poema "country clothes hung on her all and sundry" pode ser lido como uma abordagem da sexualidade feminina negra, especialmente em relação ao merchandising particular que se faz em torno do corpo da mulher afrodescendente. De modo significativo, o poema sugere expectativas de como a sensualidade da mulher negra deve ser representada. Ela seria concebida, nesse contexto, como um ser "hipersexualizado": ${ }^{2}$

country clothes hung on her all and sundry bolt of blue have mercy ink perfume that snapping turtle pussy won't let go until thunder comes

call me pessimistic but I fall for sour pickles sweets for the heat awrr reet peteet patootie

shadows crossed her face distanced by the medium riffing through it too poor to pay attention

sepia bronze mahogany say froggy jump salty jelly in a vise buttered up broke ice (De Muse \& Drudge, 1995, p. 4) roupas de roça nela e no povo todo de ímpinto tem perfume retinto de piedade que a concha xota não solta se não vem trovão me chama de pessimista é minha queda por pepinos acres doces para ardor ô coisinha tão bonitinha do pai

sombras cruzam o rosto dela e feito remoto pelo médium entre riffando-lhe pobre pacas pra pagar pra ver

sépia bronze mogno pardo sal e sapo batendo papo geléia no torno gelo bajulado e roto

${ }^{2}$ Em e-mail da autora, Harryette Mullen (c.p.) comenta, em sua interpretação do texto, que alguns versos do poema poderiam ser lidos como "incorporando uma hipérbole e/ou mitologia 
Ao discutir a tradução é possível examinar a complexidade da poética de Mullen e, especialmente, o modo como a disseminação de sentidos é produzida no processo tradutório, evidenciando, assim, a forma com que a linguagem do poema distancia-se de um tratamento que pudesse mimetizar aspectos "raciais" e/ou políticos, com a "clareza" e a "fidelidade" que se exigem tradicionalmente de uma postura engajada. $O$ poema produz a justaposição de vozes díspares, sem um eu lírico predominante, ampliando o retrato "refratado" de um mosaico que se impõe como um gesto - tanto político quanto estético - que se aproxima de uma concepção de linguagem como mestiçagem e hibridismo.

Na primeira estrofe, "bolt of blue" apresenta uma ambiguidade na medida em que a expressão remete a outra, "out of blue" ("do nada, inesperadamente"). Mas sua conexão com "country clothes" ("roupas de campo"), no verso anterior, pode nos conduzir à leitura de "bolt" como um "rolo envolto com tecido," tal como em "a bolt of blue silk" ("rolo de tecido azul"). Deve-se observar que "bolt" pode também sugerir uma forma fálica e que a interpretação de "bolt of blue", em conexão com "mercy ink perfume" ("perfume retinto de piedade"), produz uma alusão ao pênis que condiz com o próximo verso, como se afirmasse "a bolt that a snapping turtle pussy won't let go...". "Bolt of blue" foi traduzida como "de ímpinto", um portmanteau composto de duas palavras: "ímpeto" e "pinto", que apresentam sons similares, sendo também graficamente semelhantes. O emprego do portmanteau é uma forma de focalizar o movimento repentino/inesperado de "bolt of blue", ao mesmo tempo como referência implícita ao falo.

A palavra "ink", em "bolt of blue have mercy ink perfume," pode sugerir pelo menos três significados. "Ink", de modo geral, é traduzido como tinta. Mas também pode ser uma gíria que se refere à tatuagem. Como gíria afro-americana pode significar "vinho barato", bem como ser uma referência à etnicidade, tal como na gíria "inky-dinky", que significa, de acordo com o Dictionary of African American Slang, "um afro-americano bem escuro que, por acaso, está desleixado" (MAJOR, 1994, p. 251). O verso foi traduzido como "de ímpinto têm perfume retinto de piedade". O termo "ink" foi traduzido como "retinto" um adjetivo que geralmente co-ocorre com "preto" (em "preto retinto"). O vocábulo "retinto" contém o morfema "-tinto", idêntico ao adjetivo "tinto", frequentemente relacionado ao vinho, como em "vinho

acerca da sexualidade feminina negra que pode ser encontrada no blues e no folclore afro-americano, mas também em um discurso racista que identifica a mulher negra, em particular, e o negros, em geral, com o corpo/a terra/a natureza/a sexualidade de modo que a pessoa negra é vista como hipercorporificada, hipersexualizada, e animalizada. Por outro lado, há também um certo tipo de admiração ou respeito que é demonstrado em relação à sua suposta proeza sexual" (MULLEN, email da autora, 18 de novembro, 2009). 
tinto". Além disso, "retinto" pode remeter o leitor a uma palavra semelhante, relacionada a esse contexto: "tinta".

Na segunda estrofe, pode-se identificar um eu lírico que se diz atraído por "sour pickles". Como gíria, "pickle" pode significar "pênis," mas também pode se referir a uma "situação complicada". É significativo que até mesmo uma situação complicada se torne, para o eu lírico da estrofe, "sweets for the heat", traduzido como "doces para ardor". "Doces" pode ser lido como sendo tanto um substantivo quanto um adjetivo que modifica "pickles" ("pepinos") no verso anterior, atuando, assim, em um enjambement. A combinação entre "para" e "ardor" produz duas leituras simultâneas: "doces feitos para se produzir ardor" e "doces feitos para parar a dor", em vista da semelhança sonora entre "para ardor" e "parar dor". É interessante notar que essa dupla interpretação é uma possibilidade criada inesperadamente pela tradução, como uma forma de refração que, ao permitir uma multiplicidade de sentidos no texto traduzido, dialoga, na diferença, com as potencialidades semânticas da poética de Mullen.

O prazer de se olhar é uma busca desejada na medida em que a figura da mulher negra, como objeto do desejo, é trazida à tona com "awrr reet peteet patootie." "Reet" é uma gíria afro-americana para "right" ou "excelente", e "pattotie" pode significar tanto "doçura" ou "gatinha" como também "bumbum". Esse verso pode ser lido como uma alusão, levemente modificada, à canção do cantor pop afro-americano dos anos 50 e 60, Jackie Wilson, considerado um dos precursores do rhythm \& blues. A canção intitula-se "Rrr reet petite (The Finest Girl You Ever Wanna Meet)": ${ }^{3}$

Well, she really thrills me so

from her head to toe, I want the world to know

I love her, love her so

She's alright, she's alright, she's alrighty

You know to me it has to be at night

Oh, oh, oh, oh

Rrrr Reet Petite the finest girl you ever wanna meet

O verso "awrr reet peteet patootie" foi traduzido como "ô coisinha tão bonitinha do pai", uma alusão a um samba muito popular do cantor e compositor brasileiro Jorge Aragão: ${ }^{4}$

\footnotetext{
${ }^{3}$ Wilson, Jackie. The Very Best of Jackie Wilson, Ace Records UK, 2004. A canção pode ser ouvida no seguinte link: http://www.youtube.com/watch?v=xJ3-NnNx6Zs

${ }^{4}$ Aragão, Jorge. Roda de Samba com Jorge Aragão. Som Livre, 2006. A canção pode ser ouvida no seguinte link: http://www.youtube.com/watch?v=cxmFZDppfKo
} 
Você vale ouro,
todo o meu tesouro
Tão charmosa da cabeça aos pés
Vou lhe amando lhe adorando
Digo mais uma vez
Agradeço a Deus por que lhe fez
Ô coisinha tão bonitinha do pai,
Ô coisinha tão bonitinha do pai (...)

A tradução do verso como uma alusão à canção brasileira permite criar um diálogo com o jogo de intertextualidade que o poema de Mullen instaura. Embora não seja a mesma referência cultural, a busca de uma analogia com o samba inscreve o texto de Mullen na mestiçagem da tradução, possibilitando uma espécie de encruzilhada em que o rhythm \& blues e o soul se intercruzam com o samba, um ritmo que também é de origem afro.

$\mathrm{Na}$ terceira estrofe lê-se: "shadows crossed her face/distanced by the medium". Uma espécie de transe a distancia de sua própria identidade, de sua face. Ela é distanciada pelo medium, um termo ambivalente, uma vez que pode ser "aquele que diz conversar com os espíritos dos mortos" como também "o meio pelo qual algo é expresso". Os dois versos foram traduzidos como "sombras cruzam o rosto dela/ e feito remoto pelo médium." A ambivalência de "medium" em inglês não é tão facilmente reproduzida em português, já que a palavra "médium" tende a se referir apenas à "pessoa que se supõe receber mensagens dos mortos". Como forma de compensação, buscou-se criar outra alternativa de ambivalência: o verbo "distanced" foi traduzido por "e feito remoto", que possibilita interpretar "tornado remoto, distante" e "efeito remoto". Este último significado pode remeter o leitor à imagem do controle remoto, associado à televisão, mas também à ideia de que a própria mídia exerce alguma forma de influência, explícita ou implícita, sobre as mentes e os valores dos espectadores.

Os dois próximos versos em inglês, "riffing through it/ too poor to pay attention," é, possivelmente, uma alusão aos riffs de guitarra que poderiam também ser o "meio" ("the medium") através do qual ela se rende ao transe. Mullen joga com o sentido literal da expressão "pay attention" ("prestar atenção") - ela é tão pobre que não tem condições de "pagar a atenção" (tradução literal de pay attention). Ela não pode "prestar/pagar" a atenção ao próprio fato de que está em transe, de que é apenas um objeto da atenção e do desejo de outrem. O que ela pode ser, como uma mulher real, é "feito remoto" representado pelo "meio", talvez a mídia, que a tornaria, assim, um produto barato. Em português, "riffing through it" foi traduzido como "entre riffando-lhe": "riff" é um termo musical utilizado pelos guitarristas 
para se referir às "frases" musicais tocadas no instrumento. Considerou-se que seria importante manter o termo na tradução, mas conectado com outra palavra morfologicamente semelhante: "rifar". Assim, criou-se um portmanteau unindo "riff" à "rifando": "riffando." o verso "entre riffando-lhe" poderia ser lido como o gesto de se entregar aos riffs da guitarra tanto quanto ao gesto de ser "rifada", ou seja, vendida por um preço acessível.

Com a tradução de "too poor to pay attention" por "pobre pacas pra pagar pra ver", buscou-se reproduzir a ambiguidade construída sobre o sentido literal de "pagar pra ver" aliada à "pobre pacas". A aliteração produzida com a repetição da consoante "p", em "pobre pacas pra pagar pra ver", sugere a musicalidade do hip-hop, geralmente associado a alguns versos e poemas de Mullen.

o primeiro verso da última estrofe é uma combinação de palavras que se referem à variação da cor morena: "sepia bronze mahogany" ("sepia, bronze, mogno"). O verso foi traduzido como "sépia bronze mogno pardo", de modo que "pardo", um sinônimo de moreno, pudesse criar uma rima com o verso seguinte.

"Sepia bronze mahogany" rima com o verso que se segue, "say froggy jump salty". "Say froggy" é uma possível referência a uma outra expressão, "when he says frog, you'd better jump" ("quando ele disser 'rã', é melhor você pular"), que implica obediência imediata e inquestionável ao interlocutor. Por outro lado, "jump salty" é uma gíria afro-americana que significa "ficar zangado subitamente" (MAJOR, 1994, p. 265). Há ainda outra gíria afro-americana semelhante, relacionada à briga: "If you feel froggy, leap!", empregada como um desafio à luta. Ao se traduzir esse verso, considerou-se que seria importante produzir a noção de conflito inerente a essas expressões. Além disso, seria essencial buscar construções que se aproximassem das palavras "salty" e "froggy". A tradução proposta foi "sal e sapo batendo papo". Ainda que estejam "conversando", o verso traz como implicação o conflito inerente entre sapos e o sal, já que os anfíbios não suportam o contato com este, ou seja, eles têm de "pular". O verso em si é irônico no sentido de que "batendo papo", em vez de ser uma conversa amigável, pode ser literalmente o embate do "papo" do sapo com o sal, representando a imagem desesperada do animal sendo atacado. $O$ verso "sal e sapo batendo papo" apresenta assonâncias que criam um esquema rímico interno. Por outro lado, a tradução enfatiza a aliteração das consoantes "s" e "p": "sal e sapo batendo papo", evocando, assim, o som do sapo pulando. Observa-se que o verso rima com o anterior: "sépia bronze mogno pardo".

Os dois últimos versos, "jelly in a visel buttered up broke ice", podem ser lidos como uma representação simbólica do que é escorregadio. "Jelly in a vise" poderia ser interpretado como a descrição de alguém que 
consegue escapar de situações difíceis com muita facilidade. O gelo ("ice") sugere uma personalidade fria e inacessível. Assim, os dois versos foram traduzidos como "geléia no torno/ gelo bajulado e roto". Buscou-se criar um efeito aliterativo que se reproduz em "geléia", "gelo" e "bajulado". Aproximando-se do esquema rímico entre "vise" e "ice", as palavras "torno" e "roto" representam rimas finais do verso em português.

Certamente o poema de Mullen resiste à tradução, tanto quanto a tradução resiste a uma interpretação definitiva: a frase "say froggy jump salty", por exemplo, é, de certo modo, intraduzível, e imbuída de múltiplos significados em inglês. Precisamente por causa disso, torna-se possível a sua "recriação" na tradução, que expõe o leitor a campos semânticos semelhantes ao do texto original, mas somando-se a novas associações em português que não exaurem a ambivalência do verso.

\section{A POESIA NEGRA E SEUS (SUPOSTOS) LIMITES: A QUESTÃo DA MESTIÇAGEM}

A tradução comentada explicita o jogo de ambivalências que apontam para a mestiçagem linguística tanto do poema de Harryette Mullen quanto da tradução em si. Pode-se questionar, no entanto, se essa mesma mestiçagem, que produz uma resistência à inteligibilidade imediata do poema, traria consequências "limitadoras" para uma recepção mais ampla de seu trabalho, tanto nos Estados Unidos quanto no Brasil. Mullen desenvolve um questionamento crítico de noções preconcebidas a respeito da estética literária afro-americana. Essas noções remetem a expectativas que poderiam ter efeitos inibidores em relação à recepção de sua obra: espera-se que o autor negro produza seu trabalho de acordo com certas expectativas em torno de como a poesia negra deveria ser representada. Nesse contexto, o poeta ou escritor corre o risco de não ser considerado um artista "autenticamente negro", seja do ponto de vista dos negros ou dos brancos, caso seu trabalho não atenda a essas expectativas. Mullen, no entanto, questiona o que comumente se concebe como "authentic blackness", já que seu trabalho poético tem promovido um engajamento interessante com a tradição afro-americana, problematizando os requisitos exigidos para uma "verdadeira" poesia negra. A autora revê, criticamente, a estética predominante de "acessibilidade" que caracterizaria a poesia e a crítica afro-americanas (HOGUE, 2012).

A expectativa por "acessibilidade" poderia ser exemplificada com a noção de que a literatura afro-americana deveria difundir a representação da oralidade negra na literatura. O Black English Vernacular (BEV), socioleto falado por muitos afro-americanos, quando presente no texto literário, pode 
significar a necessidade de se dar voz aos afro-americanos que permanecem à margem da sociedade, já que o socioleto está muitas vezes associado à baixa escolaridade do falante. A representação da oralidade na escrita pode ser compreendida como uma forma de resistência contra o racismo e a discriminação, como, por exemplo, nos poemas de Amiri Baraka, um dos líderes do movimento Black Aesthetic ou Black Arts Movement, durante as décadas de 1960 e 1970. Por outro lado, a representação do Black English na literatura pode ser interpretada também como uma necessidade de se corresponder às expectativas dos leitores por traços da cultura negra que sejam de fácil reconhecimento e que, portanto, possam servir às demandas do mercado. Além disso, uma relação mais fidedigna entre linguagem e realidade, por meio de certo realismo, corresponderia também a uma necessidade de que a literatura negra pudesse cumprir o papel de meio através do qual as injustiças sociais poderiam ser denunciadas. Não é coincidência que Gene Jarret (2006) problematiza o que chama de "realismo racial", ao afirmar que

As antologias dão a impressão de que a literatura afro-americana deve apresentar protagonistas afro-americanos ao lado de certos temas históricos, de geografias culturais, de discursos políticos ou de subjetividades definidas racialmente. E tais textos são "autênticos" quando seus autores são identificáveis enquanto afro-americanos, não importando se esses autores desejam ou não serem caracterizados desse modo. Esses protocolos contribuem para a ideia de que o cânone, ou o "melhor" da literatura afro-americana, retrata apenas as realidades da vida negra, ou as práticas do que eu chamo de realismo racial (JARRET, 2006, p. 2).

Harryette Mullen, em seu trabalho poético, tem problematizado não somente o que se espera da poesia negra, em termos de realismo temático e linguístico, mas também a noção de que o inglês padrão, em oposição ao Black English, seria a própria língua dos brancos. Em várias entrevistas Mullen faz questão de apontar para a diversidade na sua formação linguística, uma vez que, junto à sua família, costumava falar o inglês padrão, ao passo que aprendeu a falar Black English na convivência com os amigos. No começo de sua carreira, no início da década de 80 , foi influenciada pelo Black Arts Movement, pela ênfase na oralidade e no engajamento com a questão "racial", o que fica muito claro em sua primeira obra poética, Tree Tall Woman, de 1981. Segundo a autora, à época, ela havia sido inspirada pela "ideia de que existia uma cultura negra e de que se podia escrever a partir da posição de se estar numa cultura negra" (HOGUE, 1999). No entanto, acrescenta que "[uma vez que] o projeto [do Black Arts Movement] havia criado um espaço para eu escrever [...] eu não tinha de levar em frente esse projeto, porque 
ele já havia sido empreendido; eu não tinha que dizer "sou negra, e o negro é bonito." Na verdade, na época em que eu escrevia, isso começava a ficar um pouco repetitivo e até chato" (HOGUE, 1999).

o desenvolvimento de formas poéticas experimentais, o que inclui a produção alusiva e elusiva de uma escrita que desafia classificações, representa, na poesia de Mullen, um questionamento acerca da identidade cultural, da subjetividade e da linguagem. A inovação estética de sua proposta poética amplia os próprios limites da poesia negra, repensando-a como uma forma conectiva e lúdica de se relacionar com a tradição. Obras como Trimmings, $S^{*} P^{*} R M^{*} K I T$ e Muse \& Drudge, publicadas durante a década de 90, assim como Sleeping with the Dictionary, de 2002, ampliam as fronteiras da poesia negra, conduzindo a um questionamento sobre a condição de ser negra e da negritude e de sua relação com a mestiçagem cultural, através de uma experiência estética que não deixa de ser política, ao mesmo tempo em que desafia a expectativa de que o "realismo" seja o único instrumento desejável de afirmação política e estética.

A relação da poesia de Mullen com a inovação experimental, no entanto, ensejou certos conflitos, na medida em que seus trabalhos, posteriores a Tree Tall Woman (1981), chegaram a ser compreendidas como obras "menos negras". Em uma entrevista, a autora comenta que

[...] tendo publicado Tree Tall Woman, em 1981, eu comecei a recitar poesias do livro, quando então, muitos negros compareciam às apresentações. Havia brancos, morenos e mulatos [brown people], e outras pessoas de cor também. Mas, de repente, quando comecei a fazer leituras públicas de Trimmings [1991] e de $S^{*} P^{*} R M^{*} K I T$ [1992], eu me tornei a única negra presente no recinto, lendo minha poesia. Eu me via, assim, dentro de uma sala, em que tipicamente não havia qualquer outra pessoa de cor presente - 0 que era algo, é claro, que eu poderia fazer, e era interessante... Mas não era o que eu necessariamente desejava, e então, pensei "como posso unir todas essas pessoas em uma só sala?" Muse \& Drudge foi minha primeira tentativa na busca de criar esse público. Queria que diferentes leitores de diferentes obras minhas pudessem se convergir. Estava bastante feliz em ver aquelas pessoas, interessadas em inovação formal, começarem a aparecer quando publiquei Trimmings e $S^{*} P^{*} R M^{*} K I T$, em parte, porque eu estava respondendo, nesses livros, à obra de Gertrude Stein, e, ao mesmo tempo, lidando com minhas próprias preocupações com questões de raça, gênero e cultura. [...] Nunca achei que tivesse me tornado menos negra nesses dois livros ou ficado mais negra em Tree Tall Woman. Mas creio que o modo com que essas coisas são definidas no domínio público é que, de fato, as pessoas viam $S^{*} P^{*} R M^{*} K I T$ não como um black book, mas como um innovative book. E essa ideia de que ou você é negro ou você é inovador, é algo contra o 
qual eu realmente estava lutando. E Muse \& Drudge significou a tentativa de mostrar que eu podia fazer as duas coisas ao mesmo tempo (GRIFFIN et al., 1997).

O que a autora sugere na entrevista é que a mestiçagem linguística e poética das obras produziu, especialmente a partir de Trimmings (1991), um estranhamento que levou muitos de seus leitores negros a se afastarem de suas performances públicas, já que eram mais acostumados com uma abordagem poética menos disfórica e com uma linguagem politicamente mais clara e menos ambígua. É justamente essa mestiçagem linguística que pode se tornar, talvez, um desafio para a tradução de sua obra no Brasil, especialmente quando se leva em consideração a possibilidade de tornar o seu trabalho acessível a leitores que poderiam se identificar com uma poética negra. A questão da mestiçagem ou da miscigenação é central em relação a esse aspecto, justamente porque a percepção acerca da mestiçagem na poética de Mullen não é isomórfica em relação à percepção do mesmo tema pelos afro-brasileiros politicamente engajados.

Tanto no seu discurso poético quanto no acadêmico, Mullen enfatiza a condição constitutiva da miscigenação no que tange à sua estética e à própria cultura norte-americana. Em uma entrevista concedida por ela a Calvin Bedient, isso pode ser observado:

Calvin Bedient: A linguagem em seu poema [Muse \& Drudge] tem, é claro, um aspecto mestiço [mongrel]. Há vários registros diferentes do inglês. Você acha que de certa forma este é um texto branco/negro?

Mullen: Muito já foi dito sobre como a cultura americana é miscigenada, um produto da mistura de diversas raças, culturas e línguas, e eu concordo com isso. Eu diria que sim, que meu texto é deliberadamente multívoco, que tenta expressar a diversidade real de minha própria experiência vivida aqui, exposta a diferentes culturas. "Mongrel" ["mestiço", "vira-lata"] vem de "among" ["entre"]. "Among others" ["entre outros"]. Estamos entre; não estamos sozinhos. Somos todos "mongrels" (BEDIENT, 2012, p. 186).

Não seria improvável imaginar um espaço comum entre a sua avaliação positiva da mestiçagem e o profundo processo de miscigenação no Brasil, que tem sido historicamente celebrado no país, por muitos setores, como a própria fundação da identidade brasileira, tendo possibilitado o surgimento de importantes movimentos estéticos no século XX, como o Tropicalismo, por exemplo, fundado no pressuposto da miscigenação (tanto 
biológica quanto cultural) do povo brasileiro em suas manifestações artísticas. Entretanto, historiadores e sociólogos, como Munanga (2004), têm sido críticos do louvor generalizado da noção de miscigenação, buscando demonstrar como ela participaria da sustentação do chamado mito da "democracia racial" no Brasil, com base no qual ter-se-ia criado a ilusão de um país racialmente pacífico (sem segregação), onde, na realidade, a maioria dos negros e pardos é frequentemente marginalizada e excluída de sua cidadania integral. Nesse contexto, a noção de miscigenação é, no mínimo, uma questão eivada de desconfiança, especialmente quando vista do ponto de vista dos afro-brasileiros politicamente engajados. Munanga (2004), por exemplo, assevera que "a elite brasileira, preocupada com a construção de uma unidade nacional, de uma identidade nacional, via [a] ameaça pela pluralidade étnico-racial. A mestiçagem era para ela uma ponte para o destino final: 0 branqueamento do povo brasileiro" (p. 124). O sociólogo afirma ainda que

[...] na construção do sistema racial brasileiro, o mestiço é visto como ponte transcendente, onde a tríade branco-índio-negro se encontra e se dissolve em uma categoria fundante de nacionalidade. Daí o mito da democracia racial: fomos misturados na origem e, hoje, não somos nem pretos, nem brancos, mas sim um povo miscigenado, um povo mestiço (MUNANGA, 2004, p. 131).

É na direção de uma crítica à miscigenação que uma perspectiva afro-brasileira tenderia a seguir o que Spivak (1997) denominou de "essencialismo estratégico", por meio do qual afro-brasileiros teriam que constantemente reafirmar a possibilidade de se falar em uma "essência" ou "unidade" da negritude em busca de uma inclusão social e econômica, e também de uma visibilidade cultural e estética mais contundente, em face da invisibilidade que a miscigenação, em tese, teria lhes causado.

Harryette Mullen, na condição de poetisa afro-americana, por razões históricas, poderia, talvez, mais abertamente celebrar a miscigenação como um argumento para explorar e expandir os limites da negritude em sua própria poesia, já que a noção de miscigenação nunca participou efetivamente da construção de uma "identidade nacional norte-americana", fundada justamente na imposição de uma tradição "branca" hegemônica em oposição às diferentes minorias étnicas, claramente vistas como distintas daquela. A noção de miscigenação também não exerceu uma influência na construção de um mito da democracia "racial", até porque esta nunca existiu como tal na sociedade americana, a não ser como meta a ser alcançada, como no sonho de Martin Luther King durante o movimento dos direitos civis nos anos 60 . Sem dúvida sempre houve miscigenação na sociedade americana, 
mas ela sempre foi discursivamente escamoteada, em nome da manutenção da dicotomia "branco" versus "negro", o que impediu que se reconhecesse o processo miscigenador que não só se faz presente na sociedade multicultural americana, como também chegou a "produzir" um presidente, Barack Obama, tão mestiço quanto negro. A busca por Harryette Mullen de uma experimentação estética fundada na mestiçagem e no hibridismo é uma forma de questionar, especialmente no contexto norte-americano, os limites que a oposição entre branco e negro impõe à criação literária, como se o artista negro não pudesse enveredar pelos caminhos da experimentação estética, sob o risco de ver a sua identidade artística questionada.

Já no contexto brasileiro, a mestiçagem é inscrita numa relação mais complexa entre uma posição discursiva hegemônica de louvor e outra na qual é objeto de crítica e de desmistificação. A tradução da poesia de Mullen suscita, diante desses dois discursos, uma questão central: a sua poesia poderia ser lida pelo discurso cultural vigente (inclinado a favorecer a miscigenação como uma concepção integral da identidade nacional), como um trabalho que soa sedutoramente experimental? Isso significaria torná-la "menos negra" para os padrões literários afro-brasileiros? Mullen problematiza "a ansiedade de se incorporar ou representar a identidade negra autêntica" (MULLEN, 2001, p. 1), e louva a "interrogação exploratória da identidade negra como uma formação discursiva, cultural e social [ao permitir, portanto,] que os significados da negritude se proliferem e se expandam [...], permitindo a instabilidade na definição do que a negritude é" (MULLEN, 2007, p. 68-69). Traduzir o trabalho de Mullen tendo em vista o público leitor afro-brasileiro, politicamente voltado para uma negritude "afirmativa" - ou melhor, para uma definição mais clara de negritude em face das ambiguidades geradas pela miscigenação -, significará abrir mão da instabilidade de que fala Mullen e que caracteriza seus poemas? Poderá a tradução frustrar expectativas e disseminar as diferenças (internas) que fazem da negritude um conceito sem fronteiras, mas também em constante construção?

O deslizamento de sentidos, ambivalências e disjunções da poesia de Mullen tenderiam a atrair leitores brasileiros menos afeitos às questões raciais e mais interessados no experimentalismo estético? Leitores de poesia afro-brasileira poderiam se sentir menos atraídos por tal experimentalismo, apesar do fato de que a poesia de Mullen também interage criticamente com questões de gênero e de identidade (mas de modo altamente disfórico)? Penso que sua poesia busca alcançar um público-leitor diversificado e um dos objetivos das minhas traduções foi reafirmar as possibilidades da recriação de significantes, significados e alusões que pudessem responder criticamente à riqueza de sua poesia no contexto brasileiro. 
Essas traduções poderiam desempenhar um duplo papel: oferecer uma resposta crítica ao discurso segundo o qual a poesia experimental não seria compatível com uma crítica social ou "racial"; e, por outro lado, podem também ser uma forma de questionamento do ponto de vista segundo o qual a poesia negra somente pode ser constituída com base na crítica social e "racial", distanciando-se de qualquer forma de experimentalismo. Assim, espera-se que essas traduções possam ser capazes de aproximar 0 leitor, geralmente interessado por experimentalismo, da interação com um texto que oferece uma crítica de questões de identidade cultural por meio de uma linguagem inovadora e disfórica. Por outra parte, deseja-se criar um processo de estranhamento estético positivo entre os leitores afro-brasileiros (ou atraídos por poesia negra) que poderiam se surpreender pela conjunção entre experimentalismo, linguagem dissonante e crítica étnico-social. Essa é uma experiência que pode suscitar surpresas, e até a possível (mas talvez, necessária) frustração. É o inesperado que pode ou não tornar possível uma mudança de expectativas e de avaliação por parte do leitor, caso em que ele ou ela poderá ou não refletir com maior profundidade sobre as diferentes possibilidades de representação da poesia negra, relacionando-as às diferenças e semelhanças culturais e estéticas proporcionadas pela diáspora negra.

É essencial considerar a possibilidade de que outros projetos de tradução introduzam, no sistema literário brasileiro, autores afro-americanos cujos trabalhos poéticos desestabilizam as expectativas em torno de como deve atuar a negritude no espaço estético. Essas traduções poderiam definitivamente contribuir para a necessária reavaliação que permitiria a emergência de diferentes formas de reflexão sobre as circunstâncias étnico-sociais e sobre a representação literária da identidade. Desse modo, a tradução torna-se uma forma de representação que expõe as condições tanto internas quanto externas que subjazem às formas com as quais a negritude é produzida em suas diversas variedades. Se a tradução é uma espécie de "vitrine" que, porém, supera a suposta invisibilidade de que dela se espera, o projeto tradutório viabiliza interpretações tanto do que vem "de dentro", como por exemplo, os significados da negritude no Brasil, quanto do que vem "de fora" (as representações da negritude no âmbito internacional), de modo que a concepção de blackness se constitui tanto no "reflexo" quanto na "refração" da vitrine: é, ao mesmo tempo uma, e, inesperadamente, outra.

\section{REFERÊNCIAS}

BEDIENT, C. "The solo mysterioso blues": an interview with Harryette Mullen by Calvin Bedient. In: MULLEN, H. The cracks between what we are and what we are supposed to be (Essays and Interviews). Tuscaloosa: The University of Alabama Press, 2012, p.185-203. 
FROST, E. "Ruses of the lunatic": Harryette Mullen and Lyric Hybridity. Women's Studies, v. 7, p. 464-481, 1998.

GRIFFIN, F. et al. Conversation with Harryette Mullen. 1997. Disponível em: < http://epc.buffalo. edu/authors/mullen/interview-new.html>. Acesso em: 7/7/2009.

HOGUE, C. Interview with Harryette Mullen by Cynthia Hogue. In: MULLEN, H. The cracks between what we are and what we are supposed to be (Essays and Interviews). Tuscaloosa: The University of Alabama Press, 2012, p.233-257.

JARRET, G. A. (Ed.). African American literature beyond race: an alternative reader. New York: NY University Press, 2006.

MAJOR, C. Juba to jive: a dictionary of African-American slang. New York: Penguin Books, 1994.

MULLEN, H. Recyclopedia: Trimmings, $S^{*} P e R m^{* *} K^{*} T$ and Muse \& Drudge. Saint Paul: Graywolf Press, 2006.

. Sleeping with the dictionary. Los Angeles: University of California Press, 2002.

. Tree tall woman. Energy Earth Press, 1981.

.What`s African about African American poetry?. Fence, v. 4, n. 1, Spring/Summer 2001.

Disponível em: < http://www.fencemag.com/v4n1/text/afric_amer.html>. Acesso em: 7/7/2009.

.The cracks between what we are and what we are supposed to be: stretching the dialogue of African American poetry. In: . The cracks between what we are and what we are supposed to be (Essays and Interviews). Tuscaloosa: The University of Alabama Press, 2012, p.68-76.

. Country clothes hung on her all and sundry [mensagem pessoal]. Mensagem recebida por<lauromar@ibilce.unesp.br> em 18 nov. 2009.

MUNANGA, K. Rediscutindo a mestiçagem no Brasil. São Paulo: Autêntica, 2004.

SPIVAK, G. C. “'In a word': Interview”. In: ROONEY, E.; NICHOLSON, L. (Ed.). The second wave: a reader in feminist theory. New York: Routledge, 1997. p. 356-378.

TREMBLAY-MCGAW, R. Enclosure and run: the fugitive recyclopedia of Harryette Mullen's writing. Melus, v. 35, n. 2, p. 71-94, 2010.

Submetido em: 20/04/2012

Aceito em: 24/07/2012 